\title{
Influence of environment on residence and selected demographic and clinical parameters of preschool children with IgE-dependent asthma
}

\author{
Anna Bednarek ${ }^{1, A-D, F}{ }^{\circ}$, Robert Klepacz ${ }^{2, C-F}{ }^{\oplus}$, Anna Surtel ${ }^{3, A, E-F} \oplus$, Anna Mazur, ${ }^{4, E-F} \oplus$, \\ Tomasz Saran $^{4, \mathrm{E}-\mathrm{F} \oplus}$, Danuta Zarzycka ${ }^{1, \mathrm{D}-\mathrm{F} \oplus}{ }^{\text {, Andrzej Emeryk }}{ }^{5, \mathrm{D}, \mathrm{F} \oplus}$ \\ ${ }^{1}$ Department of Paediatric Nursing, Faculty of Health Sciences, Medical University, Lublin, Poland \\ ${ }^{2}$ Department of Clinical Pathomorphology, Medical University, Lublin, Poland \\ ${ }^{3}$ Chair and Department of Periodontology, Medical University, Lublin, Poland \\ ${ }^{4}$ Department of Neuro-Rehabilitation, Institute of Rural Health, Lublin, Poland \\ ${ }^{5}$ Department of Pulmonary Diseases and Children Rheumatology, Medical University, Lublin, Poland \\ A - Research concept and design, B - Collection and/or assembly of data, C - Data analysis and interpretation, \\ $D$ - Writing the article, $E$ - Critical revision of the article, $F$ - Final approval of article
}

Bednarek A, Klepacz R, Surtel A, Mazur A, Saran T, Zarzycka D, Emeryk A. Influence of environment on residence and selected demographic and clinical parameters of preschool children with IgE-dependent asthma. Ann Agric Environ Med. 2019; 26(3): 439-444. doi: 10.26444/aaem/104666

\begin{abstract}
Introduction and objective. An important role in the pathogenesis of asthma in children is played by individual parameters and environmental factors, in particular, those related to the place of residence. The aim of this study was to assess the impact of the living environment on the basic demographic and clinical parameters of preschool children with IgE-dependent asthma

Materials and method. 176 children (126 from urban and 52 from rural areas) aged $5.22 \pm 0.34$ years, with newly-diagnosed IgE-dependent asthma, hospitalised at the Clinic for Lung Diseases and Paediatric Rheumatology of the Prof. Antoni Gębala Children's Hospital of Lublin, were qualified for the study. Medical documentation of the children was analysed, including the implementation of vaccinations. Due to the clinical form of the disease, patients were separated into groups with mild, moderate and severe asthma.

Results. No statistically significant differentiation was observed between age and current body weight and height of the children. Similarly, gender and the clinical form of asthma were not significantly correlated with the place of residence. Children with asthma, at the time of exacerbation symptoms of the disease, living in a city, significantly more often ( $p$ $<0.05)$ were treated with antibiotics in the hospital during hospitalization, while the value of OR (5.08) indicated that the rural environment enforces more frequent use of OGCs during asthma exacerbation therapy. In children from the urban environment, there was a significant correlation between the current body weight and serum calcium concentration, as well as a negative statistically significant correlation between the current body weight and serum selenium concentration. Conclusions. Residence does not determine the clinical course of IgE-dependent asthma in preschool children.
\end{abstract}

Key words

children, asthma, living environment, clinical parameters

\section{Abbreviations}

API - Asthma Predictive Index, DTaP - Vaccinated against diphtheria, tetanus and pertussis acellular, DTwP - Vaccinated against diphtheria, tetanus and pertussis with the whole-cell, GINA - Global Initiative for Asthma, GCS - Glucocorticosteroids, HBV - Vaccinated against hepatitis B, Hib - Vaccinated against haemophilus influenzae typu b, IGCs - Inhaled glucocorticosteroids, IPV - Vaccinated against poliomyelitis, LABA - Longacting inhalation $\beta 2$ agonists, MMR - Vaccinated against measles, mumps and rubella, OGCs - Oral glucocorticosteroids, PEF - Peak expiratory flow, pMDI - Pressure metered-dose inhaler, SABA - Short-acting inhaled $\beta 2$ agonists, WHO - World Health Organisation

\section{INTRODUCTION}

Asthma, heterogeneous, and one of most prevalent diseases during the developmental period, is characterised by a chronic inflammation of the respiratory tract, involving various types of cells and substances released from them. It leads to over-

Address for correspondence: Anna Bednarek, Department of Pediatric Nursing Faculty of Health Sciences, Medical University of Lublin e-mail: bednarekanna@o2.pl

Received: 10.10.2018; accepted: 11.02.2019; first published:06.03.2019 reaction of the bronchi and recurring clinical symptoms, i.e. wheezing, a sensation of pressure on the chest, and dyspnoea $[1,2]$. In children up to 5 years of age, typical symptoms of asthma also include seizures of dry, non-productive cough and respiratory difficulties manifested by reduced motor activity, sometimes leading to acute respiratory failure. They are accompanied by varied restrictions (obstruction) of the airflow through the airways, characterised by reversibility which occurs spontaneously or under medication. In half of the children up to 5 years of age, paroxysmal narrowing of the airways may be intermittent [3]. 
Pathophysiology of asthma involves a series of changes in the respiratory system affecting various subtypes of inflammatory cells, which ultimately favours airflow limitation in the lungs, and causes various clinical symptoms. The airway epithelium becomes sensitive to environmental infectious and allergic factors. Selenium and calcium are involved in immunological processes as antioxidant and T-cell activating catalysts, as well as stabilizing cellular membranes of the respiratory system, therefore they can influence the presented symptoms and course of asthma treatment [4].

According to the $\mathrm{WHO}$, the prevalence of asthma among children shows a large variation depending on the country and part of the world $(3.7 \%-26.8 \%)[5,6]$. In Europe, asthma occurs in more than $10 \%$ of children [7], while in Poland its percentage is about 8.6 [8].

An important role in the pathogenesis of asthma, on the one hand, is played by individual parameters and, on the other hand, by environmental factors, in particular those related to the place of residence. Assigning them a clear-cut role in the etiopathogenesis of the disease is difficult to define. This is due, among other things, to the significant number of genes and the high complexity of intergenerational and environmental-generational interactions. There is a view that the upward trend in the incidence of asthma in children in recent years has been caused by epigenetic modifications and environmental changes, including air pollution $[9,10,11]$.

In the urban environment, the main aeroallergens that cause symptoms of rhinitis, conjunctivitis and asthma are atmospheric air pollution by transport and industrial dust, as well as house mites and mould spores in potted flowers. On the other hand, for the rural environment, allergies to plant pollen that affect the seasonality of allergy symptoms are characteristic [12].

Genetic and environmental factors determine both the clinical picture of asthma and its phenotype, shaped by the body's immune response [13]. In children up to 5 years of age, diagnosing asthma may be difficult due to the non-specificity of symptoms. Moreover, no standardised tests are available for this age group to inspect the respiratory tract for the presence of any inflammatory processes or obstruction. The diagnosis of asthma in children $<5$ years of age is possible based on clinical assessment in line with the Asthma Predictive Index (API), the degree of effectiveness of a therapeutic trial with a low dose of inhaled glucocorticosteroids (IGCs), and the exclusion of any other causes of obstruction [14].

According to the recommendations issued by GINA 2008, asthma in children is classified, on the basis of the severity of its clinical course (episodic asthma, chronic mild, chronic moderate, chronic severe), which is of practical importance in the case of therapeutic decisions made during the first evaluation of a patient who is not treated for a chronic condition with control medicines [15].

Both the demographic division and the classification of environmental factors, important in the etiopathogenesis of asthma, are performed based on the place of residence. It is assumed that the progress of civilisation, urbanisation and industrialisation, and the resulting rise in environmental pollution in urban agglomerations, lead to an increased exposure to emissions, mainly of oxide and nitrogen dioxide. Rural areas, in turn, are liable to exposure to pollen allergens of plants (grasses, weeds and trees). Both these environments may have a significant impact on the occurrence and course of asthma [16].
The aim of this study was to assess the impact of the living environment on the basic demographic and clinical parameters of preschool children with IgE-dependent asthma.

\section{MATERIALS AND METHOD}

176 children (126 from urban and 52 from rural areas) aged $5.22 \pm 0.34$ years, with newly-diagnosed IgE-dependent asthma, hospitalised at the Clinic for Lung Diseases and Paediatric Rheumatology of the Prof. Antoni Gębala Children's Hospital of Lublin, Poland, were qualified for the study. Their medical records were analysed, also in terms of the administration of vaccinations. Due to the clinical form of the disease, patients were separated into groups with mild, moderate and severe asthma. All children during their first two years of life were vaccinated against hepatitis B (HBV), diphtheria, tetanus and pertussis (with the whole-cell DTPw or the acellular DTaP vaccine), poliomyelitis (IPV), haemophilus influenzae type b (Hib), as well as measles, mumps and rubella (MMR). Half of the children received reimbursable monovalent vaccines, while others were vaccinated with highly combined vaccines paid for by their parents.

The study was carried out in 2014-15 with the consent of the Bioethical Committee of the Medical University of Lublin (No. KE-0254/176/2011) and the hospitalised children and their parents.

Characteristics of children with asthma. Among 176 children with newly diagnosed asthma there were 97 boys (66 from urban and 31 from rural areas) and 79 girls (58 from urban and 21 from rural areas). The diagnosis was established on the basis of a modified version of the API recommended by GINA 2008 for children up to 5 years of age. In accordance with the API algorithm, children qualified for the study were those with $\geq 4$ obstruction episodes lasting at least 24 hours, including $\geq 1$ episode confirmed by a physician and at least one major (asthma in parents, atopic dermatitis, allergy to inhalation allergens) or two minor risk factors (bronchial obstruction regardless of infection, eosinophilia - above $4 \%$, allergy to food allergens) $[14,15]$. These children were also observed to experience $>1$ dyspnoea/month episode, a higher frequency of wheezing breath with whistling expiration (for which parents marked at least 3 on a scale from 1 - "rarely" to 5 - "for most days"), and a paroxysmal, dry cough associated with physical exercise.

Other obstructive diseases - cystic fibrosis, ciliary motility disorders, congenital respiratory or circulatory defects, gastroesophageal reflux, complex immunodeficiencies, tuberculosis, thoracic tumors, thyroid goiter, granulomas, as well as pertussis, atypical and Chlamydia trachomatis infections - were excluded in the examined children.

The condition of the respiratory tract in children was assessed on the basis of peak expiratory flow (PEF) measurement using a peak flow meter, a hand-held device recommended for self-control of the disease. The coefficient of variation of maximum expiratory flow (the difference between morning and evening measurements) was determined and the degree of severity and control of asthma was established. In 140 children mild, well controlled asthma (PEF variation $<20 \%$ ), in 32 children moderate, partially controlled asthma 
(PEF variation $20-30 \%$ ) and in 4 children severe asthma (PEF variation $>30 \%$ ) were found. Skin prick tests were performed and total IgE levels were determined in peripheral blood as part of allergy examinations. In all children, IgE, selenium and calcium concentrations fell within appropriate reference ranges.

The children were receiving treatment in accordance with the current recommendations $[17,18]$. In those with mild and moderate clinical form of the disease, low-dose IGCs control therapy was applied; 100-200 ug of Budesonide with permanent and temporary bronchodilator SABA using a pressurised metered-dose inhaler (pMDI), and in the case of children aged 4-6 years a mouthpiece inhalation chamber was used. Bronchial obstruction rarely disappeared spontaneously in children, but would always subside when subjected to treatment. Less than $4 \%$ of the respondents required the use of GCS currently or in the past on a systemic basis, i.e. orally (OGCs).

In the case of children with severe asthma (4 persons, 2 each from urban and rural areas) the therapy had to be periodically intensified through a 4 -fold increase in the IGCs as compared to the previous dose (400 ug Budesonide) for 7 days. Furthermore, an OGCs (lowest effective dose) and slowrelease methylxanthines (theophylline), as well as LABA, i.e. Salmeterol, were included for 7-14 days.

Based on an interview with the parents and an analysis of hospital documentation, information on selected demographic features and the current health status of children was obtained. A family burden of allergic diseases was found in all study subjects.

There were no coexisting diseases or disorders of somatic and psychomotor development in children. The children came from complete families who cooperated in the treatment and self-control of the disease. Data on vaccinations carried out, their timeliness and the vaccines used were obtained from the medical records of the examined children (health booklet in the part concerning vaccinations).

Children were hospitalized due to the need to perform diagnostic tests or modification of therapy due to prolonged infections of the lower respiratory tract.

Serological evaluation. IgE, selenium and calcium concentrations were determined in serum. The tests were carried out by the ALAB Medical Analyses Laboratory in Lublin. Total IgE concentration was determined using the chemiluminescence method with the ADVIA Centaur $\mathrm{XP}$ apparatus. The standard (reference range) for IgE is: in children $1-4$ years old $-0.4-351.6 \mathrm{IU} / \mathrm{ml}, 5-10$ years old $-0.5-$ $393 \mathrm{IU} / \mathrm{ml}$. Selenium concentration was determined by mass spectroscopy (ICP-MS) with the X-Series II ICP-MS apparatus (Thermo Scientific, ALAB Medical Analyses Laboratory, Germany). standard level of selenium concentration in preschool children - 23-114 $\mu \mathrm{g} / \mathrm{L}$. Calcium concentration in serum was determined with the ADVIA 1800 apparatus using the colorimetric method (Arsenazo III). Standard level calcium concentration in children - 8.4-10.4 mg/dl.

Statistical analysis. Statistical characteristics of continuous variables are shown as arithmetic means and their standard deviations (SDs). Normal distribution of continuous variables was verified with the Shapiro-Wilk test. The distribution type and statistical significance of intergroup differences were verified with the Student t-test or the Mann-Whitney
U-test. Distributions of discrete variables are presented as numbers and percentages; their intergroup comparisons were based on the chi-squared test and the Fisher exact test. Correlation analysis was performed by the Spearman correlation coefficient.

Correlations between the place of residence and data from the analysed medical records were estimated based on an odds ratio (OR). All calculations were carried out with the Statistica 12 software package (StatSoft, Tulsa, OK, USA). Statistical significance threshold for all tests was set at $\mathrm{p}<0.05$.

\section{RESULTS}

Table 1. Place of residence vs. gender and anthropometric parameters of children with asthma

\begin{tabular}{lccccc}
\hline & \multicolumn{2}{c}{$\begin{array}{c}\text { Urban area } \\
(n=124)\end{array}$} & \multicolumn{2}{c}{$\begin{array}{c}\text { Rural area } \\
(n=52)\end{array}$} & $\mathrm{p}$ \\
\cline { 2 - 5 } & $\mathrm{M}$ & SD & $\mathrm{M}$ & $\mathrm{SD}$ & \\
\hline Age (years) & 5.20 & 0.39 & 5.23 & 0.37 & 0.6139 \\
\hline Current body weight $(\mathrm{kg})$ & 20.57 & 4.15 & 20.00 & 3.60 & 0.3870 \\
\hline Current body height $(\mathrm{cm})$ & 118.38 & 5.51 & 118.23 & 4.70 & 0.8654 \\
\hline
\end{tabular}

The place of residence did not have any statistically significant differentiation effect on age and the current body weight and height of the children (Tab. 1).

Table 2. Place of residence vs. gender and clinical form of asthma

\begin{tabular}{llccccc}
\hline & & \multicolumn{2}{c}{ Urban area } & \multicolumn{2}{c}{ Rural area } & \multirow{2}{*}{$p$} \\
\cline { 2 - 5 } & & $n$ & $\%$ & $n$ & $\%$ & \\
\hline \multirow{2}{*}{ Gender } & Boys & 66 & 53.23 & 31 & 59.62 & \multirow{2}{*}{0.4368} \\
\cline { 2 - 6 } Clinical asthma & Girls & 58 & 46.77 & 21 & 40.38 & \\
\cline { 2 - 6 } & Severe & 2 & 1.61 & 2 & 3.85 & \\
\cline { 2 - 6 } & Mild & 97 & 78.23 & 43 & 82.69 & \multirow{2}{*}{0.4065} \\
\cline { 2 - 5 } & Moderate & 25 & 20.16 & 7 & 13.46 & \\
\hline
\end{tabular}

No statistically significant correlation was observed between gender and clinical form of asthma and place of residence (Tab. 2).

Table 3. Place of residence vs. titre of skin prick tests

\begin{tabular}{|c|c|c|c|c|c|c|}
\hline & & \multicolumn{2}{|c|}{$\begin{array}{c}\text { Urban } \\
\text { area }\end{array}$} & \multicolumn{2}{|c|}{ Rural area } & \multirow[t]{2}{*}{$\mathrm{p}$} \\
\hline & & $n$ & $\%$ & $n$ & $\%$ & \\
\hline \multirow{3}{*}{$\begin{array}{l}\text { Titre of } \\
\text { skin prick } \\
\text { tests for } \\
\text { airborne } \\
\text { allergens }\end{array}$} & Large (blister diameter $>6 \mathrm{~mm}$ ) & 18 & 14.52 & 11 & 21.15 & \multirow{3}{*}{0.4340} \\
\hline & Medium (blister diameter 3-6 mm) & 32 & 25.80 & 10 & 19.23 & \\
\hline & Small (blister diameter < $3 \mathrm{~mm}$ ) & 74 & 59.68 & 31 & 59.62 & \\
\hline \multirow{3}{*}{$\begin{array}{l}\text { Titre of } \\
\text { skin prick } \\
\text { tests } \\
\text { for food } \\
\text { allergens }\end{array}$} & Large (blister diameter $>6 \mathrm{~mm}$ ) & 18 & 14.52 & 6 & 11.54 & \multirow{3}{*}{-0.6690} \\
\hline & Medium (blister diameter 3-6 mm) & 44 & 35.48 & 22 & 42.31 & \\
\hline & Small (blister diameter $<3 \mathrm{~mm}$ ) & 62 & 50.00 & 24 & 46.15 & \\
\hline
\end{tabular}

Place of residence of the analysed children with asthma did not have a statistically significant differentiation effect on the titre of skin prick tests in such children (Tab. 3). 
Table 4. Place of residence vs. data from the medical history of children

\begin{tabular}{|c|c|c|c|c|c|c|c|c|c|}
\hline & & \multicolumn{2}{|c|}{ Urban area } & \multicolumn{2}{|c|}{ Rural area } & \multirow{2}{*}{$\mathrm{p}$} & \multirow{2}{*}{ OR } & \multirow{2}{*}{\multicolumn{2}{|c|}{$95 \% \mathrm{Cl}$}} \\
\hline & & $n$ & $\%$ & $n$ & $\%$ & & & & \\
\hline \multirow{2}{*}{$\begin{array}{l}\text { Past childhood } \\
\text { diseases* }\end{array}$} & No & 109 & 87.90 & 44 & 84.62 & \multirow{2}{*}{0.5540} & \multirow{2}{*}{1.32} & \multirow{2}{*}{0.52} & \multirow{2}{*}{3.34} \\
\hline & Yes & 15 & 12.10 & 8 & 15.38 & & & & \\
\hline \multirow{2}{*}{$\begin{array}{l}\text { Antibiotic } \\
\text { treatment during } \\
\text { hospitalisation }\end{array}$} & No & 33 & 26.61 & 22 & 42.31 & \multirow[b]{2}{*}{$<0.05$} & \multirow[b]{2}{*}{0.49} & \multirow[b]{2}{*}{0.25} & \multirow[b]{2}{*}{0.98} \\
\hline & Yes & 91 & 73.39 & 30 & 57.69 & & & & \\
\hline \multirow{2}{*}{$\begin{array}{l}\text { Use of OGCs during } \\
\text { hospitalisation }\end{array}$} & No & 122 & 98.39 & 48 & 92.31 & \multirow{2}{*}{0.0636} & \multirow{2}{*}{5.08} & \multirow{2}{*}{0.90} & \multirow{2}{*}{28.67} \\
\hline & Yes & 2 & 1.61 & 4 & 7.69 & & & & \\
\hline
\end{tabular}

Urban children with asthma were treated with antibiotics significantly more often $(\mathrm{p}<0.05)$ during hospitalisation, while the OR value (5.08) indicated that the rural environment necessitates a more frequent use of OGCs during the hospitalised therapy of asthma (Tab. 4).

Table 5. Place of residence vs. type and timeliness of vaccinations in children with asthma

\begin{tabular}{|c|c|c|c|c|c|c|c|c|c|}
\hline & & \multicolumn{2}{|c|}{$\begin{array}{c}\text { Urban } \\
\text { area }\end{array}$} & \multicolumn{2}{|c|}{ Rural area } & \multirow{2}{*}{$p$} & \multirow{2}{*}{ OR } & \multicolumn{2}{|c|}{$95 \% \mathrm{Cl}$} \\
\hline & & $n$ & $\%$ & $n$ & $\%$ & & & & \\
\hline \multirow{2}{*}{$\begin{array}{l}\text { Type of } \\
\text { vaccines } \\
\text { administered }\end{array}$} & $\begin{array}{l}\text { Mono- } \\
\text { valent }\end{array}$ & 63 & 50.81 & 25 & 48.08 & \multirow{2}{*}{0.7411} & \multirow{2}{*}{1.12} & \multirow{2}{*}{0.58} & \multirow{2}{*}{2.13} \\
\hline & $\begin{array}{l}\text { Highly } \\
\text { combined }\end{array}$ & 61 & 49.19 & 27 & 51.92 & & & & \\
\hline \multirow{2}{*}{$\begin{array}{l}\text { Timeliness of } \\
\text { vaccinations }\end{array}$} & No & 42 & 33.87 & 17 & 32.69 & \multirow{2}{*}{0.8799} & \multirow{2}{*}{1.05} & \multirow{2}{*}{0.53} & \multirow{2}{*}{2.10} \\
\hline & Yes & 82 & 66.13 & 35 & 67.31 & & & & \\
\hline
\end{tabular}

Retrospective evaluation of administered compulsory preventive vaccinations during early childhood or their timeliness did not have any significant differentiation effect on children with regard to place of residence (Tab. 5).

Table 6. Place of residence vs. concentrations of analysed parameters

\begin{tabular}{lccccc}
\hline & \multicolumn{2}{c}{$\begin{array}{c}\text { Urban area } \\
(\boldsymbol{n}=\mathbf{1 2 4})\end{array}$} & \multicolumn{2}{c}{$\begin{array}{c}\text { Rural area } \\
(\boldsymbol{n}=\mathbf{5 2})\end{array}$} & $\mathrm{p}$ \\
\cline { 2 - 6 } & $\mathbf{M}$ & SD & $\mathbf{M}$ & $\mathbf{S D}$ & \\
\hline $\mathrm{Ca}(\mathrm{mg} / \mathrm{dl})^{*}$ & 8.80 & 1.22 & 8.72 & 1.39 & 0.7391 \\
\hline $\mathrm{Se}(\mu \mathrm{g} / \mathrm{L})^{* *}$ & 61.31 & 14.71 & 61.60 & 14.53 & 0.9806 \\
\hline $\mathrm{IgE}(\mathrm{IU} / \mathrm{ml})^{* * *}$ & 181.00 & 129.12 & 164.58 & 116.96 & 0.7044 \\
\hline
\end{tabular}

*Ca calcium; **Se selenium; ***IgE total immunoglobulin $\mathrm{E}$

The place of residence did not have a statistically significant effect on the values of the analysed biochemical parameters (Tab. 6).

Evaluation of correlations between parameters. In contrast to children from rural areas, those living in an urban environment exhibited a statistically significant correlation between the current body weight and serum calcium concentration, as well as a negative statistically significant correlation between the current body weight and serum selenium concentration (Tab. 7 and 8 ).
Table 7. Living in an urban area and assessment of correlations between analysed parameters

\begin{tabular}{lcccc}
\hline & $\begin{array}{c}\text { Current body } \\
\text { weight }\end{array}$ & $\begin{array}{c}\text { Current body } \\
\text { height }\end{array}$ & Calcium & Selenium \\
\hline Current body weight & & $\mathbf{0 . 8 5 7 2 *}$ & $\mathbf{0 . 2 1 7 9 *}$ & $\mathbf{- 0 . 2 6 9 *}$ \\
\hline Current body height & $\mathbf{0 . 8 5 7 2 *}$ & & 0.1850 & -0.1437 \\
\hline Calcium & $\mathbf{0 . 2 1 7 9 *}$ & 0.1850 & & 0.0622 \\
\hline Selenium & $\mathbf{- 0 . 2 6 9 0 *}$ & -0.1437 & 0.0622 & \\
\hline
\end{tabular}

* statistically significant correlation

\section{DISCUSSION}

Based on epidemiological studies in the last decades, an increase in the incidence of allergies, including asthma in Poland and many Western countries is observed. Given the rapid changes in the prevalence of symptoms of multiorgan allergy in children over short periods of time, it has been assumed that environmental factors related to, among others, the place of residence, may serve to provide the most probable explanation for this trend $[1,2,5,6,19]$.

Studies worldwide have revealed a lower incidence of allergic diseases in rural/agricultural areas. At present, it is believed that the place of residence may indicate specific conditions related to individual and natural microbiomes which affect the undertaking of a particular lifestyle by a given community, and which most likely also impact on the proper functioning of the immune system [20]. In own study, the vast majority of children came from the urban environment $(n=126)$, while 52 children came from rural areas, which determined the specific effect of allergens (pollen of plants, molds and animal allergens) as risk factors for asthma exacerbation.

The phenotype of atopic (allergic) asthma dominates in about $85 \%$ of patients under 18 years of age. The essence of atopy is the genetically determined tendency to overproduction of $\operatorname{IgE}$ in response to exposure to allergens. The central role in the development of asthma is played by airborne (inhaled) allergens, i.e. house dust, plant pollen, moulds, animal antigens, and those resulting from exhaust emissions and industrial pollution $[7,12,21]$.

Combined with air pollutants, allergens have an increased allergenic potential. Dirt particles can be transported on the surface of pollen grains or remain suspended in the air. They cause an irritating reaction and facilitate the penetration of the allergen through the mucous membranes and skin. Air pollutants may increase sensitivity to allergens by directly affecting the respiratory tract mucosa, and in particular by boosting epithelial permeability associated with oxidative damage, which facilitates the penetration of allergens [22].

Children are particularly vulnerable to air pollution due to the immaturity of their immune and respiratory systems. A systematic review of 13 studies published by Braback et al. [23] confirms the contribution of air pollutants to the aetiology of allergic respiratory tract symptoms in healthy children.

It has been proved that prenatal exposure to air pollution caused by car traffic, as well as living in a polluted area immediately after childbirth, increases the risk of early whistling in infants and is associated with the development of asthma in children under 7 years of age [24]. 
Jackson et al. [25] describes the interactions of allergies and infections with genetic and environmental factors affecting the immune system and respiratory tract and thus contributing to the development of asthma. Ierodiakonou et al. analysed the influence of nitric oxide $(\mathrm{NO})$, tropospheric ozone (O3) and carbon monoxide (CO) pollutions over a 4 -year period in a group of 1,000 children [26]. Deterioration in pulmonary function was observed in children during periods of increased concentration of the examined gases. In addition, the short-term effect was more manifested in children treated with IGCs.

The element analysed next was the diversity of the gastrointestinal microbiome composition, which is considered to be one of the factors determining the development of non-specific immunity. The influence of environmental microbiomes in rural areas can counteract the development of allergies and asthma [27].

Recurrent respiratory infections, mainly of viral aetiology, constitute a major environmental risk factor for asthma symptoms in pre-school children. These tend to be protracted infections, usually without fever, which also hinder the implementation of preventive vaccinations [28].

Most infections in pre-school children can be effectively prevented by vaccination. The majority of vaccines are administered in infancy and early childhood, i.e. in the periods of intensive maturation of the immune system and child's development. During this time, the child usually receives a complete list of scheduled doses of basic vaccination against various infectious diseases. In preschool and school years, preventive vaccinations are supplemented by a booster vaccination programme. All children participating in the authors' own study underwent a full-dose mandatory vaccination programme, with the majority of them (63.13\% from urban and $67.31 \%$ from rural areas) receiving vaccines within the due timeframe, regardless of place of residence.

Asthma may affect children's physical development, resulting in a characteristic delayed pattern of growth and pubescence. The key factors likely to disturb normal development include chronic tissue hypoxia, recurrent respiratory infections, weakened lung function, chronic stress and sleep disorders associated with dyspnoea at night [21].

In authors' own study, the current anthropometric parameters (body weight and height) of preschool children with asthma from both analysed environments corresponded to normal values and the place of residence did not differentiate them in a statistically significant manner.

Selenium concentration may affect the system of immune defence concerning, on the one hand, humoral and, on the other hand, the cellular and antioxidant response of the system. Studies have shown a relationship between the concentration of serum selenium and a reduced risk of childhood asthma $[29,30]$. In addition, a diet rich in this element or its supplementation has been, in the case of asthma, recognised as a therapeutic alternative [31].

Calcium presents a multidirectional effect on the immune system, mainly through the release of inflammatory mediators from basophilic cells of the immune system and the activation of T lymphocytes by means of calcineurine protein, which reduces the permeability of respiratory cell membranes for microorganisms and significantly impacts on the proper course of the division of immune cells of the circulatory system (lymphocytes and granulocytes) [32, 33].
The production of IgE antibodies in response to environmental factors occurs primarily in the phenotype of allergic asthma in children, a disease which was also found in all patients in the current study [7].

In a case-control study, children from rural schools in Nigeria to study the relationship between serum micronutrients and asthma were shown decreased calcium levels and increased selenium concentration in children with asthma, compared to the control group. In their conclusions, the authors of the study found that the protective effects or risk associated with the state of micronutrients in the body of children with asthma justify the need for further research [34]. In this study, the concentrations of selenium (23-114 $\mu \mathrm{g} / \mathrm{L}$ for children aged 5 years), calcium (1-18 years old; $8.4-10.4 \mathrm{mg} / \mathrm{dl})$ and total serum IgE (1-4-years-old; 0.4-351.6 IU/ml and 5-10-years-old; 0.5-393 IU/ml), fell within the range of clinical standards for a given age and did not vary significantly depending on the living environment.

The place of residence may determine the specificity of allergens and the availability of contact with a specialist physician. People living in rural areas are more frequently exposed to allergens (plant pollen, animal allergens) and more likely to experience difficulties in accessing medical care $[35,36]$. In this study, children living in urban areas were administered antibiotics significantly more often during hospitalisation, which determined the course of asthma, perhaps also due to the specific features of urban environment pollution. On the other hand, the use of GCS was significantly more frequent in the case of hospitalisation of children from rural areas. This is probably due to less accurate asthma control conditioned by the availability of regular access to a physician and control tests.

The study by Li et al. [16] showed that the prevalence of asthma, just as correct diagnosis and therapy coefficients, were much higher in urban than in suburban and rural areas. At the same time, compared to their urban peers, rural children used antibiotics and IGCs more often in the therapy of asthma exacerbation.

The prevalence and control of the disease depends on the gender of the patient. Among children up to pubescence, asthma affects about $5.1 \%$ of boys and about $3.5 \%$ of girls [6]. Studies emphasise that girls with asthma significantly more often report its symptoms and experience its negative symptoms for longer periods of time. On the other hand, among male children twice more frequent recurrent asthma and asthma were found in the first years of life $[33,35]$. No statistically significant correlations between gender and asthma were found in the authors' own study.

The absence of direct environmental impacts on anthropometric parameters (body weight, height) and serum-based factors assigned to the immune system (Se, Ca) may indicate a limited role of the place of residence in the etiopathogenesis of IgE-dependent asthma. However, the correlations revealed for the current body weight and the concentrations of selenium and calcium in children living in urban areas may be arguments in favour of a slightly different, environmentally conditioned clinical picture of the disease. This is additionally evidenced by the administration of antibiotics and GCS to children showing dependence on the place of residence. 


\section{CONCLUSION}

Residence does not determine the clinical course of IgEdependent asthma in preschool children.

\section{REFERENCES}

1. Federico MJ, Hoch HE, Anderson WC, Spahn JD, Szefler SJ. Asthma Management for Children Risk Identification and Prevention. Advances in Pediatrics 2016; 63: 103-126.

2. Hatzler L, Hofmaier S, Papadopoulos NG. Allergic airway diseases in childhood - marching from epidemiology to novel concepts of prevention. Pediatr Allergy Immunol. 2012; 23: 616-622.

3. Han MK, Agusti A, Calverley PM, Celli BR, Criner G, Curtis JL, et al. Chronic obstructive pulmonary disease phenotypes. The future of COPD. Am J Respir Crit Care Med. 2010; 182: 598-604.

4. Tagiyeva N, Devereux G, Fielding S, Turner S, Douglas G. Outcomes of childhood asthma and wheezy bronchitis - a 50-year cohort study. Am J Respir Crit Care Med. 2016; 193: 23-30.

5. World Health Organization. Technical Briefing. Asthma and COPD interventions for the Appendix 3 of the Global Action Plan for Non Communicable Disease. Geneva, 2017.

6. Szefler SJ, Gergen PJ, Mitchell H, Morgan W. Achieving asthma control in the inner city: do the National Institutes of Health Asthma Guidelines really work? J Allergy Clin_Immunol. 2010; 125(3): 521-6.

7. Guilbert TW, Mauger DT, Lemanske RF. Childhood asthma - predictive phenotype. J Allergy Clin Immunol Pract. 2014; 2: 664-70.

8. Jutel M. Rozpoznawanie chorób alergicznych w podstawowej opiece zdrowotnej. Podsumowanie zaleceń grupy ekspertów EAACI 2014 (The diagnosis of allergic diseases in primary health care. Summary of the recommendations of the EAACI 2014 expert group). Med Prakt. 2014; 7-8: 60-68 [in Polish].

9. Bowatte G, Lodge C, Lowe AJ, Erbas B, Perret J, Abramson MJ, et al. The influence of childhood traffic-related air pollution exposure on asthma, allergy and sensitization: a systematic review and a meta-analysis of birth cohort studies. Allergy 2015; 70: 245-256.

10. Brunst KJ, Ryan PH, Brokamp C, Bernstein D, Reponen T, Lockey J, et al. Timing and Duration of Trafficrelated Air Pollution Exposure and the Risk for Childhood Wheeze and Asthma. Am J Respir Crit Care Med. 2015; 192: 421-427.

11. Jung DY, Leem JH, Kim HC, Kim JH, Hwang SS, Lee JY, et al. Effect of Traffic-Related Air Pollution on Allergic Disease: Results of the Children's Health and Environmental Research. Allergy Asthma Immunol Res. 2015; 7: 359-366.

12. Huang S, Wang JH, Huang SK, Yan L, Lan L, Hong J, et al. Survey on the correlation factors of the pathogenesis of asthma in children in Guangzhou community. J Practical Med. 2010; 26: 3240-3.

13. Koczulla AR, Vogelmeier CF, Garn H, Renz H. New concepts in asthma: clinical phenotypes and pathophysiological mechanisms. Drug Discov Today 2017; 22(2): 388-96.

14. Castro-Rodriguez JA, Holberg CJ, Wright AL, Martinez FD. A clinical index to define risk of asthma in young children with recurrent wheezing. Am J Respir Crit Care Med. 2000; 162: 1403-6.

15. Global Strategy for Asthma management and prevention, Global Initiative for Asthma (GINA) Update 2008. http://www.ginasthma.org.

16. Li M, Zhang Q, Shi WJ, Li L, Yan L, Ying P, et al. Epidemiological survey and analysis of asthma in children aged $0-14$ years old in urban and rural areas of Chengdu region. Transl Pediatr. 2013; 2(4): 160-166.
17. Chung KF, Wenzel SE, Brozek JL, Bush A, Castro M, Sterk PJ, et al. International ERS/ATS guidelines on definition, evaluation and treatment of severe asthma. Eur Respir. 2014; 43: 343-373.

18. Hagan JB, Samant SA, Volcheck GW, Li JT, Hagan CR, Erwin PJ, et al. The risk of asthma exacerbation after reducing inhaled corticosteroids: a systemic review and meta-analysis of randomized controlled trials. Allergy 2014; 69: 510-516.

19. Genuneit J. Exposure to farming environments in childhood and asthma and wheeze in rural populations: a systematic review with meta-analysis. Pediatr Allergy Immunol. 2012; 23: 509-518.

20. von Mutius E. The microbial environment and its influence on asthma prevention in early life. J Allergy Clin Immunol. 2016; 137: 680-9.

21. Heinrich J. Influence of indoor factors in dwellings on the development of childhood asthma. J Hyg Environ Health. 2011; 214(1): 1-25.

22. Brandt EB, Biagini Myers JM, Ryan PH, Khurana Hershey GK. Air pollution and allergic diseases. Curr Opin Pediatr. 2015; 27: 724-735.

23. Braback L, Forsberg B. Does traffic exhaust contribute to the development of asthma and allergic sensitization in children: findings from recent cohort studies. Environ Health 2009; 8: 17-28.

24. Brunst KJ, Ryan PH, Brokamp C, Bernstein D, Reponen T, Lockey J, et al. Timing and Duration of Trafficrelated Air Pollution Exposure and the Risk for Childhood Wheeze and Asthma. Am J Respir Crit Care Med. 2015; 192: 421-427.

25. Jackson DJ, Gern JE, Lemanske RF Jr. The contributions of allergic sensitization and respiratory pathogens to asthma inception. J Allergy Clin Immunol. 2016; 137: 659-65.

26. Ierodiakonou D, Zanobett A, Coull BA, Melly S, Postma DS, Boezen HM, et al. Ambient air pollution, lung function and airway responsiveness in asthmatic children. J Allergy Clin Immunol. 2016; 137: 390-9.

27. von Mutius E. The microbial environment and its influence on asthma prevention in early life. J Allergy Clin Immunol. 2016; 137: 680-9.

28. Pegas PN, Alves CA, Scotto MG, Evtyugina MG, Pio CA, Freitas MC. Risk factors and prevalence of asthma and rhinitis among primary school children in Lisbon. Rev Port Pneumol. 2011; 17(3): 109-116.

29. Hoffmann PR. Asthma in children and nutritional selenium get another look. Clin Exp Allergy. 2011; 42: 488-489.

30. Fernanda M, Carneiro H, Rhoden CR, Amantéa SL, Barbosa F. Low Concentrations of Selenium and Zinc in Nails are Associated with Childhood Asthma. Biol Trace Elem Res. 2011; 144: 244-252.

31. Jacobson GA, Yee KC, Ng CH. Elevated plasma glutathione peroxidase concentration in acute severe asthma: comparison with plasma glutathione peroxidase activity, selenium and malondialdehyde. Scand J Clin Lab Invest. 2007; 67: 423-430.

32. Lezmi G, Gosset P, Deschildre A, Abou-Taam R, Mahut B, Beydon N, et al. Airway remodeling in preschool children with severe recurrent wheeze. Am J Respir Crit Care Med. 2015; 192: 164-71.

33. Anderson WC III, Szefler SJ. New and future strategies to improve asthma control in children. J Allergy Clin Immunol. 2015; 136(4): 848-59.

34. Oluwole O, Arinola OG, Adu MD, Adepoju A, Adedokun BO, Olopade OI, et al. Relationships between Plasma Micronutrients, Serum IgE, and Skin Test Reactivity and Asthma among School Children in Rural Southwest Nigeria. J Mol Biomark Diagn. 2014; ID 106150: 1-9.

35. Ly NP, Gold DR, Weiss ST, Celedon JC. Recurrent wheeze in early childhood and asthma among children at risk for atopy. Pediatrics. 2006; 117: e1132-1138.

36. Bednarek A, Bodajko-Grochowska A, Bartkowiak-Emeryk M, Klepacz R, Ciółkowski J, Zarzycka D, Emeryk A. Demographic and medical factors affecting short-term changes in subjective evaluation of asthma control in adolescents. Post Dermatol Alergol. 2018; 35, 3: 259-266.

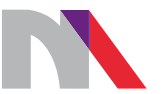

\section{Ministry of Science} and Higher Education

Republic of Poland

Generation of the DOI (Digital Object Identifier) - task financed under the agreement No. 618/P-DUN/2019 by the Minister of Science and Higher Education 